\title{
“Entre el espanto y la ternura": voces de colaboración y resistencia en el Chile de la transición
}

\author{
La Flaca Alejandra | Carmen Castillo | 1994 \\ Ignacio Albornoz Fariña*
}

Université Paris VIII Vincennes-Saint-Denis, Francia

Recibido: 10 de enero 2019; aceptado: 19 de febrero 2019

\begin{abstract}
Resumen
El presente artículo se propone analizar el filme La Flaca Alejandra: vidas y muertes de una mujer chilena, realizado en 1994 por Carmen Castillo y Guy Girard. Inscrita en el marco de la transición post-dictatorial, la cinta gira en torno a la figura de Marcia Merino (alias La Flaca Alejandra), militante del MIR convertida en colaboradora del régimen militar bajo la presión de sus torturadores. A lo largo del texto, se argumentará que el filme de Castillo funciona como espacio de una doble "puesta en escena del yo"; espacio en el que se cruzan dos trayectorias divergentes -la de la autora, Carmen Castillo, también presente en la imagen, y la del sujeto filmado, la colaboradora Marcia Merino. En tanto que instancia de un retorno doble a la escena del trauma, la empresa de La Flaca Alejandra, será finalmente interpretada como una tentativa de poner en contacto, aunque sin forzarlas a alcanzar una síntesis, dos voces testimoniales acaso irreconciliables.
\end{abstract}

Palabras Clave: Marcia Merino | Carmen Castillo | transición | documental político | voz.

"Between Fright and Affection": Voices of Betrayal and Resistance in the Chilean Transition to Democracy

Abstract

The present article seeks to study the film La Flaca Alejandra: vidas y muertes de una mujer chilena, made by Carmen Castillo and Guy Girard in 1994. Produced during the period of the democratic transition, the film focus on the figure of Marcia Merino (political name "La Flaca Alejandra"), far-left militant who became a collaborator of Pinochet's regime under torture. Throughout the text, it will be argued that Castillo's film functions as a site for the establishing of a double "mise en scène" of the 'self'; a place where two divergent life trajectories intersect with each other: that of the filmmaker, present as well in the image, and that of the filmed subject, the "symbol of treason" Marcia Merino. As an instance of a two-fold return to the scene of the trauma, the endeavor of La Flaca Alejandra will finally be understood as an attempt to put into contact, albeit without forcing them to reach a synthesis, two irreconcilable testimonial voices.

Key Words: Marcia Merino | Carmen Castillo | transition | political documentary | voice

"Entre el espanto y la ternura crece la hiedra.

En sano juicio con la locura, la flor, la piedra” Silvio Rodríguez

“...pero ahora con cierta tristeza porque estaban todos tan quebrados" José Donoso, La desesperanza

\section{Introducción}

Escritora, cineasta y activista política, Carmen Castillo ha realizado hasta la fecha más de diez filmes docu- mentales, de temas diversos. Una constante, sin embargo, recorre su obra: el estudio y evocación de las violencias y exacciones del régimen militar de Pinochet, del cual fue víctima, sino directa, al menos colateral.

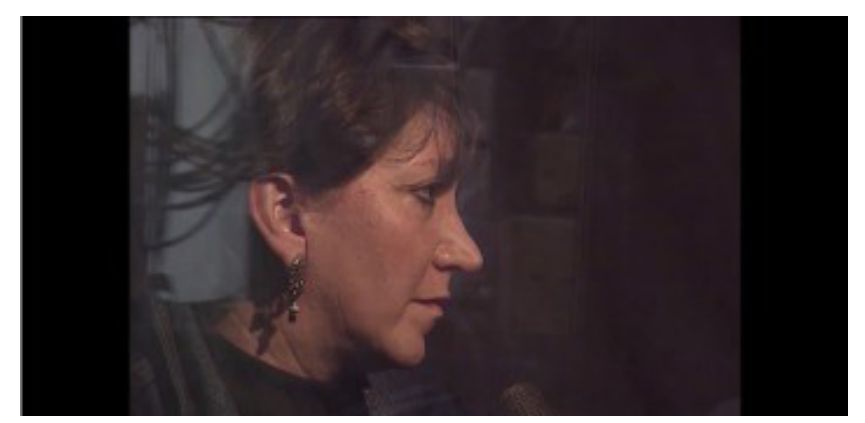

ignacio.n.albornoz@gmail.com 
Cuatro de sus cintas exploran, en efecto, motivos ligados a los traumas del pasado reciente del Chile de la dictadura: Los muros de Santiago (1983), La flaca Alejandra (1994), El país de mi padre (2004) y Calle Santa $\mathrm{Fe}$ (2007). Con un estilo personal, que navega cómodamente entre el relato íntimo, autobiográfico, y una suerte de reactivación de los grandes discursos políticos, estos cuatro filmes componen una especie de saga, marco de trabajo indispensable a la hora de analizar los arabescos de la memoria chilena en el cine documental; asimismo, sitúan a su realizadora entre los cultores de aquella corriente retórica que el historiador italiano Enzo Traverso denominaba "la memoria de los vencidos" y que definía como un "lenguaje visual capaz de hacerse cargo del eclipse de la esperanza socialista y de la herencia de las revoluciones fracasadas del siglo pasado" ${ }^{1}$ (Traverso E. , 2016, p. 103).

En el presente artículo, quisiera analizar una de las obras a mi parecer más interesantes de la "saga chilena" de Castillo: La flaca Alejandra, filme co-realizado junto al francés Guy Girard y que celebra en 2019 su vigesimoquinto aniversario. Mi hipótesis a lo largo del texto será que este filme representa una instancia-acaso la primera en el contexto de la transición democrática en Chile- de un retorno doble, dialógico, a la escena del trauma. En otras palabras, argumentaré que la cinta es el espacio de una doble "puesta en escena del yo"; espacio en el que se cruzan dos trayectorias divergentes -la de la autora, Carmen Castillo, presente en la imagen, y la del sujeto filmado, la colaboradora del régimen militar Marcia Merino.

Intentaré desarrollar mi hipótesis de lectura, en primer lugar, a través de la evocación -forzosamente brevede los itinerarios político-mediáticos de ambas mujeres; esto, con el objetivo de poner en evidencia "la abrasiva historial personal y pública que [las] conecta” (Traverso A., 2017, p. 99). Realizaré luego un breve análisis de la estructura de la cinta, así como de los distintos tipos de imagen fílmica que esta pone en contacto. Situándola finalmente en la corriente del documental "performativo"2 (Bruzzi, 2006; Nichols, 2017; Valenzuela, 2006) subrayaré enseguida un elemento de su tejido cinematográfico que contribuye a enriquecer su apuesta narrativa, a la vez que le confiere unidad y coherencia: la contigüidad y superposición de voces resistentes y colaboradoras en un mismo espacio sonoro. Para esto, movilizaré las nociones de voz en off y voz out, según la definición del crítico francés Serge Daney. Una premisa teórica, cuya formulación particular tomo prestada a Diamela Eltit, escritora chilena, subyacerá a lo largo de mi razonamiento; a saber que "toda autobiografía está inserta en un proceso de escritura de la memoria y por ello no puede ser leída literalmente como verdad, sino más bien como una teatralización del yo, como puesta en escena biográfica, donde el yo activado en el texto es, especialmente, ficcional" (103).

\section{Auto-Semblanzas de "La Flaca"}

"La Flaca" es el alias político de Marcia Alejandra Merino Vega (Concepción, 1948), personaje desconcertante y polifacético como hay pocos: miembro activo del MIR durante los años sesenta y setenta, Merino fue, según sus propias palabras, consignadas en Mi verdad: más allá del horror, yo acuso..., libro autobiográfico publicado en 1993, una "militante rígida y dura" (Merino, 1993, p. 6), fascinada ante "el gran intento histórico de transformar la sociedad y hacerla justa” (Merino, 1993, p. 6).

Temida por algunos de sus subalternos, su función dentro del partido, en la época del Golpe, escribe, era "obtener infraestructura (casas) de seguridad para los miembros de la Comisión Política del MIR" (Merino, 1993, p. 9). Luego de una primera detención infructuosa efectuada algunas semanas después del Golpe, Merino, según su propio testimonio, habría sido amenazada por otro militante del MIR, Guillermo Retamal Jara, quien le habría dicho: "te tenía reservada una bala si hablabas" (Merino, 1993, p. 15), aparentemente en razón de la importancia de la información que manejaba. En 1974, sin embargo, no correría la misma suerte. Durante los primeros días del mes de mayo, Merino cae en manos de los servicios de inteligencia de Pinochet, cuyos agentes, luego de innombrables sesiones de tortura y vejámenes, logran doblegarla y hacerla hablar. Merino entrega entonces el paradero de un buen número de camaradas de la Resistencia y delata a otros tantos. Comienza, para ella, "una espiral sin retorno" (Merino, 1993, p. 6), que resume de la siguiente manera: "Sentí que todo había terminado para mí. Había traicionado lo que más amaba en ese entonces" (Merino, 1993, p. 6).

Merino describe en un par de párrafos, con sangre fría y un estilo desprovisto de cualquier ornamentación, el tormento creciente e incontrolable de sus dieciocho años como colaboradora, que la llevaron incluso a convertirse en funcionaria civil asalariada de los servicios secretos de información, destino que compartió 
junto a Luz Arce y María Alicia Uribe, también ex-miristas (Traverso A. , 2017, p. 99; Matus; Eltit, 1996, p. 102): "Durante largo años, viví en un territorio de nadie, arrastrando un pasado que no quería reconocer [...]. ¡Cuántas veces anhelé contar mi verdad! Cuántas veces esos anhelos fueron bloqueados, no solo por temor a perder la vida, sino por temor a no ser creída. En toda esa época mi dilema fue elegir entre la muerte y la muerte... [...]" (Merino, 1993, p. 7).

Ahora bien, la colaboración de Merino con los servicios de inteligencia militar (primero la DINA y luego la $\mathrm{CNI}$ ), no se acaba ni con la disolución de la primera ni mucho menos con el retorno a la democracia, obstinación que alimentó seguramente su reputación de leyenda negativa en el imaginario social, en el que ocupó "el lugar de la delación y de la traición” (Eltit, 1996, p. 112). Como recuerda Diamela Eltit, Merino seguiría ligada de alguna u otra manera al mundo militar, en el que cosechó éxitos y distinciones, hasta el año 1992 (Eltit, 1996, p. 111): “a lo largo de 15 años, Luz Arce y Marcia Alejandra Merino se abocaron a alcanzar un escalafón social y económico en el interior de un sector de las fuerzas armadas" (Eltit, 1996, p. 111).

Es solo a fines de 1991 que abogados de la Comisión de Verdad y Reconciliación logran dar con el paradero de Merino, "[quien] reconoció, desde la primera declaración, que había entregado a camaradas suyos en la tortura, varios de los cuales desaparecieron" (Matus \$2). En noviembre de 1992 Merino organiza una conferencia de prensa en la sede de la Comisión Chilena de Derechos Humanos -suerte de ritual público de mea culpa, al que se añadiría más tarde, para completar la purga, la publicación del volumen autobiográfico mencionado más arriba-, con el objetivo declarado de "pedir perdón" 3 . Durante los primeros minutos de La Flaca Alejandra, Castillo se refiere al evento con las siguientes palabras: "Marcia Merino, la "Flaca Alejandra”, la mujer cuya traición desencadenó la caída de nuestra red, ha decidido romper dieciocho años de colaboración con la DINA. [...] Acepta entregar su testimonio contra los militares y frente a todos pide perdón” (Castillo, 1994).

\section{El lento camino hacia la imagen: Castillo y la aprehensión del mal}

Es precisamente en el contexto de la reaparición pública de Merino en 1992 -evento calificado en el filme como "hecho nuevo que permite reconstruir la otra cara de esta historia" (Castillo, 1994)- que Castillo decide entrevistarse con La Flaca, personaje que, según sus propias palabras, habría marcado, tanto en el plano intelectual como emotivo, "su existencia en el exilio" (Lazzara, 2012, p. 10).

Cabe recordar que Castillo dejó Chile dramáticamente en 1974, luego de que la Dirección Nacional de Inteligencia del régimen de Pinochet allanara su casa de la Calle Santa Fe (comuna de San Miguel), en una operación que terminaría con la muerte de su compañero Miguel Henríquez, secretario general del Movimiento de Izquierda Revolucionaria (MIR). Aunque Castillo es más bien vaga a este respecto, es posible conjeturar que las delaciones de La Flaca tuvieron un impacto considerable en la desarticulación de la red de información del MIR y, por consecuencia, en la localización y caída de la casa de calle Santa Fe (Traverso A., 2017, p. 99). Ahora bien, este punto, como recuerda Antonio Traverso, es omitido durante el filme, lo que otorga al gesto reconciliatorio de Castillo para con La Flaca una capa adicional de complejidad y polémica. Apunta Traverso: "Castillo ni siquiera formula el asunto de la caída de la casa como pregunta cuando conversa con Merino en pantalla. Al contrario, [...] Castillo, contra toda lógica, ni confronta ni interroga a Merino" 4 (Traverso A., 2017, pp. 99-100).

Para Castillo, enfrentarse a Merino es, como se ve, un desafío personal. En términos cinematográficos, se trata de un premier esfuerzo cinematográfico de reconstrucción de su propia experiencia traumática, que se completará solamente, según consigna la literatura, con el impresionante trabajo memoria que representa Calle Santa $F e$, cinta filmada en Chile entre 2002 y 2007 (Raymond, 2011, p. 146).

En el plano intelectual, explica con más detalle la propia Castillo, el conocimiento del caso de La Flaca la lleva a familiarizarse con todo un corpus literario y teórico en torno a la problemática del mal y del testimonio: "Estudié y trabajé durante años sobre el rol del testigo, sobre aquello que Giorgio Agamben dice acerca de los testigos en Auschwitz, acerca de quién habla en el nombre de quién. Leí y estudié todos los escritos de Primo Levi. Medité en torno a la pregunta: ¿qué sobrevive de la memoria de los muertos?" (Lazzara, 2012, p. 11). Al mismo tiempo que estas reflexiones sobre el miedo, la tortura y la traición se decantan, madura en Castillo el deseo de realizar una obra cinematográfica, que su primer filme, Los muros de 
Santiago, producido para la televisión francesa en 1983 con el objetivo declarado de exponer la fisionomía física y moral de un pueblo bajo dictadura, anuncia de cierto modo, aunque sin lograr satisfacerlo del todo. Así, aunque su primer reflejo luego de las declaraciones públicas de La Flaca es escribir un libro en torno al caso, Castillo decide finalmente verter su experiencia en la producción de un filme, elección que explica del siguiente modo: "Hay un cuerpo, un individuo que personifica los dos lados de la historia. Y esa persona puede contar la historia" (Lazzara, 2012, p. 11). La realización de La Flaca Alejandra, en ese sentido, debe ser comprendida como el corolario de un proceso de reflexión en torno al mal, la traición y la tortura que comenzaba ya, de manera bastante temprana, con la redacción del libro testimonial Un jour d'octobre à Santiago, publicado en Francia en 1980, en el que la figura de Merino ocupaba un sitio no desdeñable. Como señala la propia cineasta: "Llegué a hacer esa película después de un enorme trabajo con la memoria, en el pensamiento y en la emoción” (Bedregal, 1999).

\section{Una imagen múltiple}

En términos concretos, las entrevistas de Castillo con Merino se llevan a cabo en seis locaciones distintas, seis "momentos" dialógicos consignados aquí según su orden de aparición: (a) asiento trasero de un automóvil, en que Merino reconstituye sus sesiones de "poroteo" 6; (b) habitaciones de la casa de tortura de la calle José Domingo Cañas; (c) salón de un restorán en el que La Flaca reconoce fotografías de sus antiguos colegas de la DINA, cuyos perfiles sicológicos y comportamientos, enseguida, describe; (d) observación de filmes e imágenes de archivo en una sala de montaje; (e) encuentro con Alicia Barrios, ex-mirista, en las escolleras de Playa Ancha; y (f) entrevista con Gladys Díaz, sobreviviente de la tortura, periodista y antiguo miembro de la dirección del MIR, en los estudios de Radio Nacional.

Estos seis “momentos" de diálogo, en los que Merino puede entregarse de manera más o menos libre a la evocación y reconstitución de sus recuerdos de militancia, tortura y colaboración, son interrumpidos y puntuados, durante los sesenta minutos de duración del filme, por otras tantas secuencias en las que el cuerpo de Merino no figura en pantalla. Estas secuencias, me parece, vienen a señalar algo así como pausas, temps morts en los que una experiencia fílmica de carácter más contemplativo y abstracto puede manifestarse y ganar terreno. Durante estas secuencias se tratará, pues, de mettre en avant sobre todo la subjetividad de la propia realizadora, que aprovecha estos intervalos de "suspensión testimonial" para abandonarse a su vez a un ejercicio de remembranza de ribetes a ratos poéticos, líricos.

Tres tipos de imagen, que me gustaría evocar aquí según un orden creciente de abstracción, sirven de soporte a las cavilaciones y pensamientos que Castillo, astutamente, enlaza en estos intervalos. En primer lugar, habría que consignar aquellas en que su cuerpo es perceptible de facto en la imagen, ya sea dentro o fuera de campo. Como ya lo he sugerido de cierta forma en la primera parte de este artículo, estas secuencias ilustran, por regla general, desplazamientos de "acercamiento" o "aproximación”, efectuados ya de cuerpo entero, ya de manera tangencial, por intermedio de la voz o de la mirada.

En todos los casos, se trata siempre de un dirigirse-hacia indicios, lugares, objetos o personas que la realizadora desea afrontar, observar o interrogar. Así, la cámara nos muestra a Castillo, en una de las primeras escenas, caminando hacia la casa de calle Santa Fe, sitio de memoria que servirá para gatillar de cierto modo el relato de la historia de La Flaca; más tarde, nos la revelará deambulando entre las tumbas anónimas del Cementerio General, mientras su voz, dominando la banda sonora sobre una música de cuerdas, se pregunta: “¿Cómo llenar el vacío que quedó en tantas y tantas vidas, sin denominar las víctimas, sin nombrar los asesinos?" (Castillo, 1994). Algunos minutos más adelante, y como para dar respuesta a esta interrogante, la cámara exhibe a Carmen Castillo y Alicia Barrios en frente del Mural del Detenido Desaparecido ${ }^{7}$ y del Ejecutado Político, destino de su deambulación, ubicado en el patio 102 del mismo Cementerio General, sobre cuya superficie figuran, esculpidos en granito, los nombres completos de "todas las víctimas de la dictadura reconocidas por el Estado" (Amorós, 2006, p. 11). Otras instancias de "acercamiento" -esta vez por medio de la voz-son los cuatro planos en los que Castillo intenta comunicarse por teléfono, infructuosamente, con el coronel Miguel Krassnoff Marchenko, "agente operativo encargado de eliminar al MIR [durante la dictadura]” (Matus $\$ 17$ ), o aquellos en que la cineasta visita e interroga al torturador Osvaldo Romo, calificado por Nelly Richard como "una de las figuras más sórdidas de la represión militar” (Richard, 2010, p. 77). 


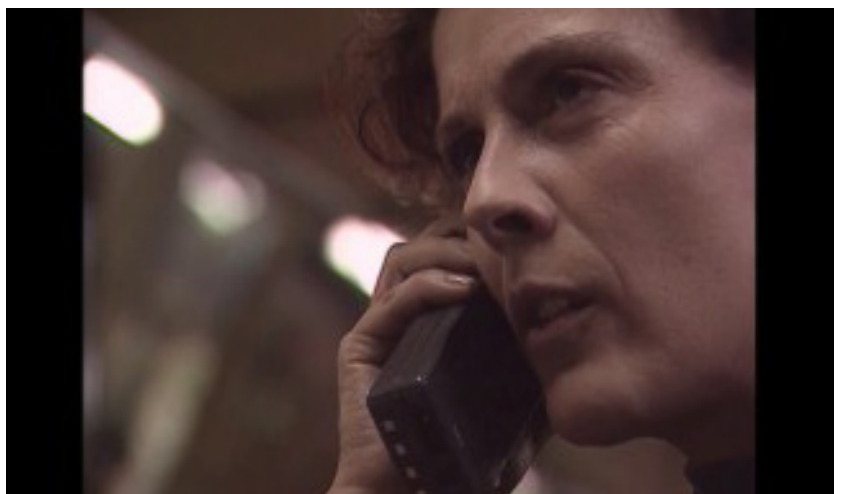

El segundo tipo de procedimiento visual empleado durante las ausencias de Merino en pantalla es utilizado, a menudo, para registrar imágenes de archivo, fijas o móviles. Fotografías íntimas, retratos oficiales, recortes de periódicos, son capturados por una cámara febril, trémula, en movimiento constante. Así, en una de las primeras secuencias, mientras la cámara recorre rápidamente una serie de fotografías de desaparecidos, amigos personales de la realizadora, esta habla por ejemplo de "rostros arrancados del olvido, inmóviles". El contraste entre texto e imagen, aquí, resulta interesante y simboliza, de manera bastante transparente, la empresa de recuperación memorial que Castillo se propone; a saber, la "reactivación", a través de la imagen y del testimonio, de aquellas parcelas anquilosadas de la memoria histórica nacional, las referidas a las atrocidades del régimen militar.

En tercer lugar están las imágenes, más abstractas, aunque igualmente convulsas y agitadas, con las que Castillo ilustra, aproximándolas -y en un gesto que autoriza ciertamente el apelativo de "experimental" con el que Macarena Gómez-Barris califica el filme-, dos realidades complementarias: el descenso de La Flaca hasta el abismo de la delación y la traición y el estado actual de olvido que domina al país en el contexto postraumático de la transición. El imaginario que domina estos fragmentos que navegan por lo demás entre la ficción y el documental es, como la misma Gómez-Barris lo reconoce, el de la tortura, que es entendida como una experiencia de fractura (Merino utilizará frecuentemente el verbo "quebrarse" durante sus monólogos ${ }^{8}$ ), en la que "las certezas de las lógicas dominantes a propósito de la traición, la confesión y los juicios sobre las mujeres 'traidoras'" (Gómez-Barris, 2015, p. 533) parecen disolverse: "La cámara está en constante movimiento, como imitando los viajes del torturador de un lugar a otro, y la dislocación espacio-temporal de la que es víctima la captiva” (Gómez-Barris, 2015, p. 533).
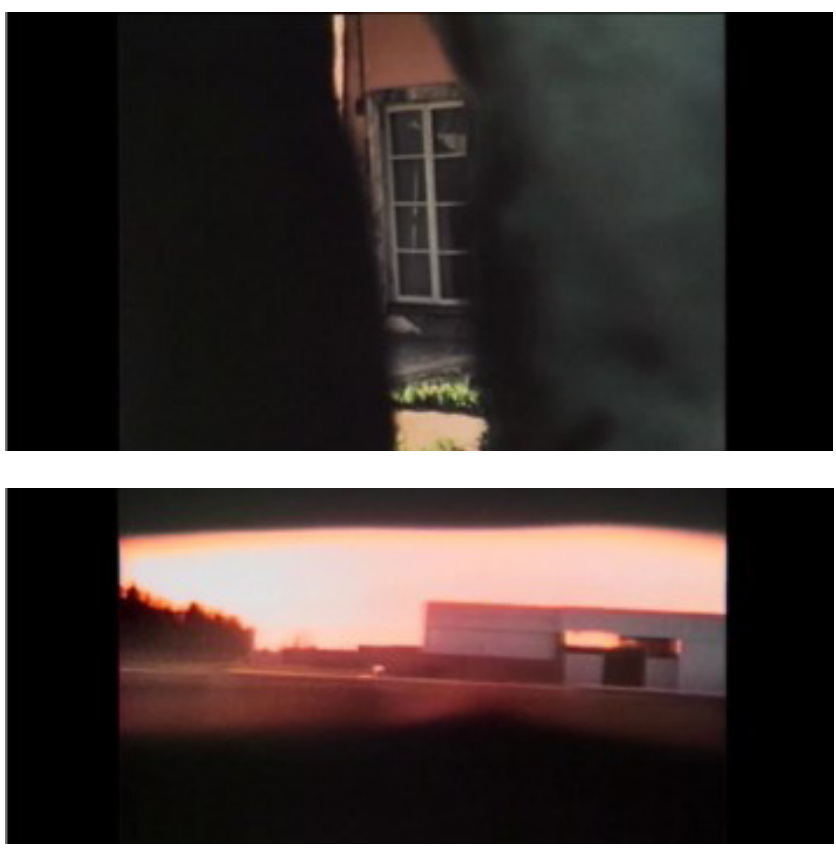

Ese efecto de disolución de los principios éticos que domina la empresa del filme tendrá, durante las secuencias evocadas, un correlato en el campo de lo visual, anulando todo punto de referencia físico, confundiendo puntos de vista y perspectivas. Las imágenes vagas, difusas y fragmentarias, "a menudo demasiado oscuras para ser descifradas" " (Gómez-Barris, 2015, p. 533) de las que Castillo se sirve no se dejarán, pues, interpretar fácilmente. A medio camino entre la textura del video y del filme Super-8, su identificación requerirá de una observación detenida, debido, también, a la potencia ficcionalizante que en cierto modo las anima.

No es en absoluto anodino, en este sentido, que el filme comience con este tipo de imagen, entregando una visión de un Santiago patibulario, nocturno y azafranado, que se repetirá en varias ocasiones a lo largo del relato, aunque según distintas variaciones cromáticas. En todos los casos, mientras desfilan en la pantalla vistas móviles de la ciudad, tomadas desde la altura de un edificio situado en los nuevos barrios acomodados del Sector Oriente, el texto de Castillo apuntará a la amnesia (disolución de la memoria, pero también de la identidad) que, apenas tres años después del fin de la dictadura, parece haberse apoderado del país: "Santiago", afirma por ejemplo Castillo hacia la mitad del filme, "se ve tan ajeno, indiferente a esta historia. Esta ciudad de noche podría ser Berlín, Houston, París: torres, avenidas, autos, mercancías. [...] Una sociedad entera obligada a no ver, no oír, no saber. Una sorda amenaza exige que se olvide, que se olvide incluso que hay algo que olvidar" (Castillo, 1994). 


\section{El film como comunidad de voces}

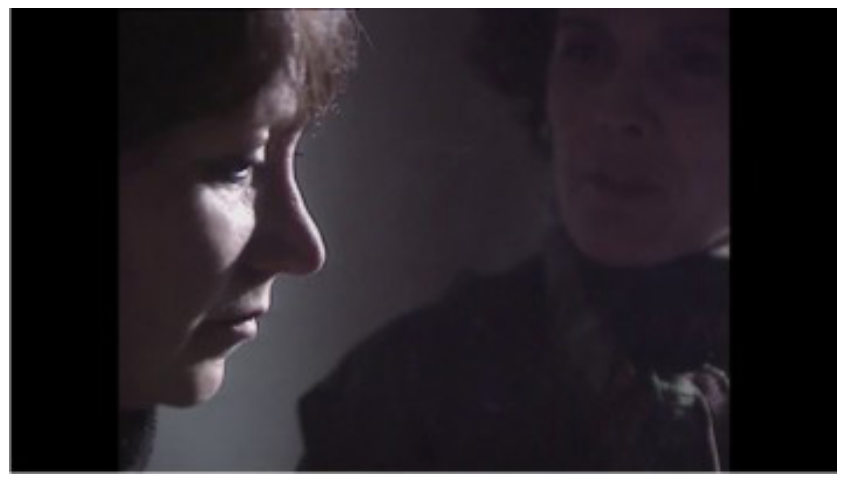

En “Mon ennemi préféré ?", artículo publicado en el número veintitrés de la revista francesa Images Documentaires, Jean-Louis Comolli anota: "Amigos o enemigos, los personajes de un filme comparten [un] ambiguo destino escénico [...]. No solamente pertenecen al mismo filme, sino a menudo al miso cuadro [...]. Nace entre ellos una especie de comunidad cinematográfica" ${ }^{[10]}(\mathrm{Co}-$ molli, 1995, p. 50). En términos visuales, desde luego, la evidencia de esta comunidad resulta irrefutable si se considera el caso de La Flaca Alejandra. En efecto, y como lo ha señalado ya Antonio Traverso, uno de los primeros aspectos de la puesta en escena que llaman la atención es la permanente proximidad física de Castillo y Merino: "Castillo", escribe Traverso, "prefiere sentarse o estar de pie cerca de Merino, como si estuviera en compañía de una vieja compañera, en vez de posicionarse fuera de campo, frente a su sujeto, como un entrevistador -o un interrogador- lo haría" ${ }^{11}$ (Traverso A. , 2017, p. 100).

Ahora bien, la observación de Comolli -me parece- es válida tanto para los cuerpos capturados por el objetivo de la cámara como para los discursos que estos mismos vehiculan y emiten. Así, en La Flaca Alejandra, además de una comunidad corporal, existiría una comunidad sonora, manifestada principalmente por la yuxtaposición de dos voces divergentes - la de La Flaca y la de Castillo-, a las que se añadirán, como soportes, otras voces reales o virtuales, correspondientes también a dos universos en pugna: la voz de Osvaldo Romo y la novoz silenciada, huidiza, de Krassnoff en el frente de los victimarios y las voces de Alicia Barrios, Miriam Ortega y Gladys Díaz por el bando de la resistencia.

Los estatutos de ambas voces principales, sin embargo -y aquí radica justamente todo el interés cinematográfico de la empresa de Castillo-, no son equivalentes: una -la de Merino- se encuentra circunscrita fundamentalmente, como ya se ha dicho, al espacio escénico, al interior del campo; la otra -la de la cineasta- englobará en cambio el relato desde un sitial diferente, abstracto, que no es simplemente el del fuera de campo (durante las entrevistas, el cuerpo de la realizadora está de facto presenté casi a todo momento en la pantalla).

Sería acaso útil introducir aquí, para distinguir estas dos modalidades, la distinción que realiza el crítico francés Serge Daney entre la voz out, emitida "dentro" de la imagen, y la voz en off, "cuya emisión resulta invisible" (Daney, 2004, p. 170). La primera sería "la voz según sale de la boca. Chorro, deyección, desecho. Una de esas cosas que el cuerpo expulsa" (Daney, 2004, p. 170). Este tipo de voz implicaría, continúa Daney, una suerte de fetichismo del momento de la emisión, del "espectáculo de la boca” (Daney, 2004, p. 171). La voz en off, en cambio, provendría de un "espacio imaginario" (Daney, 2004, p. 170) y poseería, en virtud de la alianza que forma con él, un efecto de activación presente sobre la mirada del espectador, "una especie de estar-ahí" (Daney, 2004, p. 168). "Montada a posteriori sobre la imagen", la voz en off "va siempre paralela al desfile de [esta], [...] no [la] recorta nunca” (Daney, 2004, p. 168).

Lo interesante de la apuesta de Castillo es que la autora restringe a su mínima expresión sus intervenciones durante las entrevistas con Merino -las instancias de su voz in ${ }^{[12]}$, diría Daney- , limitándose, como ya señalaba Traverso, a "[escuchar] calmadamente los monólogos de la otra, $[\ldots]$ aunque siempre observando intensamente cada gesto y movimiento" (Traverso A. , 2017, pp. 99100). Esta, desde luego, es una elección deliberada de puesta en escena, aunque determinada en parte, como la propia Castillo lo confiesa en la cinta, por su incapacidad personal para confrontar a Merino de manera directa: " $[s]$ oy incapaz de sacudir, de hacer las preguntas necesarias" (Castillo, 1994). Con todo, la decisión es tal que permea incluso el dispositivo de realización del filme, como explica la cineasta: "con Guy Girard nos impusimos ciertas 'instrucciones de uso': no debía haber intercambios con la Flaca antes de la filmación. Toda nuestra relación tenía que ser frente a la cámara” ${ }^{[13]}$ (Castillo, 1994).

Para contrarrestar pues el discurso de la Flaca y no "caer en la trampa de su palabra" (Castillo, 1994), Castillo imagina dos soluciones, ambas de orden fílmico: la primera es entrar en la imagen, de cuerpo entero, aparecer en pantalla junto a Merino, idea que le es sugerida por el co-realizador de la cinta, el francés Guy Girard (Castillo, 1994). Sin este gesto, admite Castillo, "estaríamos encerrados en el discurso de la Flaca, lo cual habría sido nefasto para el relato" ${ }^{14}$ (Castillo, 1994). La segunda -insisto sobre este punto- es controlar y reducir su pro- 
pio uso de la palabra hablada durante los diálogos con la ex-colaboradora, renunciando a ofrecer su voz por intermedio de aquel "espectáculo de la boca" del que habla Daney.

Al confinar el discurso de la Flaca a la sola manifestación de una voz out, al dejarla monopolizar el espacio escénico de la entrevista y negar de paso, para sí misma, la posibilidad de una voz que salga "del cuerpo filmado" (Daney, 2004, p. 170), Castillo opera una diferenciación de estatus discursivo entre ella y su sujeto, creando algo así como una jerarquía ontologica de voces. El cuerpo de Merino, cuyo único medio de expresión es precisamente la voz out, nos es entonces revelado en toda su dimensión de fachada, de apariencia o, como diría Daney, de añagaza: "[l]a voz out sale del cuerpo filmado que es un cuerpo absolutamente problemático, una falsa superficie y una falsa profundidad, un doble fondo de algo que no tiene fondo" (Daney, 2004, p. 170).

La voz de Castillo, al contrario, al no reposar sobre un doble visual reducido al "espectáculo de la torsión y dibujo de los labios" (Daney, 2004, p. 168), se dirige de modo más directo al espectador, y adquiere, por contraste, un mayor espesor. A esto viene a añadirse todavía otro aspecto, si se quiere material. En La Flaca Alejandra, la voz en off de Castillo funciona, es cierto, como hilo conductor y gozne articulatorio de los distintos tipos de imágenes descritas en el inciso precedente. Pero, al mismo tiempo -y quizás de manera igualmente importante- por las particularidades tímbricas y sonoras que le son propias, se distingue inconfundiblemente de la voz de Merino. Y es que, aunque contiguas en el espacio sonoro, ambas voces poseen en efecto características físicas singulares, reconocibles con facilidad. El timbre es quizás la más palpable de ellas: si la voz de Carmen Castillo es grave, áspera y rotunda, la de Marcia Merino, ya desde la primera secuencia al borde del llanto, resulta en comparación aguda, seca, a ratos delicada y flemática, aunque no por ello abúlica o dubitativa.

El discurso de Merino, a pesar de la suavidad de su cadencia, es las más de las veces certero y lúcido, preciso sus giros léxicos y en las imágenes que evoca; literario, afectado, incluso en los momentos de mayor emotividad, como cuando Alicia Barrios la interpela directamente a propósito de sus delaciones. No es sorprendente, pues, que la última intervención de La Flaca en el filme sea, casi literalmente, sacada de un libro. "Si entrego este testimonio ahora”, escribía Merino en Mi verdad, "es porque más allá de mi deseo de volver a la vida, está la aspiración de alcanzar justicia. Quiero entregar mi verdad y con ella deseo aportar al conocimiento del horror vivido por mí y por muchos [...]”. (Merino, 1993, p. 7). En la cinta, en cambio, declarará: "Para mí es fundamental reconstruir no solo mi memoria, sino la memoria de un país. Porque son muchos y miles los que murieron y son muchos los dañados, los que sobrevivimos con daño, con un daño terrible. Es una sociedad entera que está enferma de miedo" (Castillo, 1994).

Ahora bien, dirá el observador crítico, Castillo cultiva también, en sus filmes, algunos de los temas que ha tratado ya en sus múltiples libros y publicaciones. Cierto. La diferencia, sin embargo, radica aquí en la posición de ambas voces. Pronunciada, como lo es, dentro de la imagen, en tanto que voz out, la perorata de Merino no hace más que señalar su estatuto de repetición, de artificio, de engañosa abundancia o profundidad. El cuerpo de la voz out, explica no sin humor Daney, "expulsa [...] determinados objetos con la misma generosidad con la que en los taxis de Buster Keaton caben regimientos" (Daney, 2004, p. 170).

\section{Conclusiones}

Como se ha intentado argumentar a lo largo de estas páginas, el filme de Carmen Castillo está lejos de buscar responder de modo taxativo a la pregunta por el estatuto jurídico o ético de La Flaca. Desde luego, la cuestión puede insinuarse a ratos, tangencialmente, en razón de lo abrasivo del tópico tratado. Lo cierto, en cualquier caso, es que la cinta no orbita en torno al dilema de la inocencia. "Tú culpabilidad no me interesa”, escribía ya Castillo a Merino en una de las cartas que sellaron la participación de esta última en el documental. "Hablamos aquí de un trabajo", continuaba enseguida, "de un trabajo para intentar comprender la máquina de muerte [de la dictadura]" (Castillo, 1994).

El juicio moral, desde el inicio del filme, se encuentra suspendido, anulado, pues, como explica la propia Castillo: "Ya muy tempranamente en mis reflexiones, supe que lo que sucedió bajo la tortura solo puede ser visto y analizado por la gente que la sufrió. Es imposible aprehenderla desde afuera" (Lazzara, 2012, p. 10). Este, curiosamente, es el mismo razonamiento que hasta cierto punto desarrolla Diamela Eltit en "Cuerpos nómadas”: “¿Desde qué lugar”, se pregunta la escritora, "podía yo juzgar la situación de mujeres violadas, torturadas, encarceladas en un medio feroz que yo, desde otro lugar, también había habitado?" (Eltit, 1996, p. 109). Y Merino, sin ir más lejos, también 
se sirve de este raciocinio al ser interrogada por Alicia Barrios en una de las últimas secuencias de la cinta. "¿Tú fuiste torturada?”, demanda entonces La Flaca a su interlocutora, en un tono de ligera exasperación. Ante la respuesta negativa de Barrios, Merino concluye: "No podrías comprenderlo, porque no lo viviste” (Castillo, 1994).

Evacuada pues la cuestión de la responsabilidad de La Flaca ${ }^{15}$-de cualquier modo "[1] os contornos que acusan y disfrazan el perfil de la traición", nos dice Nelly Richard, "son ellos mismos traicioneros" (Richard, 2010, p. 103)-, el gesto esencial del filme corresponde, me parece, a la apertura de un espace de parole doble, reflexivo y hasta cierto punto alegórico, en el que visiones divergentes y antagónicas del conflicto chileno pueden coexistir, sin por ello verse obligadas a sublimarse en una síntesis final.

Por lo pronto, este carácter irresoluto, suspendido, se encuentra en perfecta armonía con el estado de cosas del país durante la filmación de la cinta. Al dejar en suspenso, en efecto, la resolución de los dilemas éticos levantados (el filme se cierra, en clave un tanto pesimis- ta, con una cuarta llamada infructuosa al coronel Krassnoff), Carmen Castillo nos recuerda al fin que "el Chile de la transición vive bajo los signos amenazantes de una traición perpetua" (Richard, 2010, p. 104).

En ese contexto, la coexistencia a la que hago referencia no puede equivaler, desde luego, a un consenso. Al contrario, y como ya se ha afirmado, la contigüidad de cuerpos y voces colaboradoras y resistentes se inscribe dentro de un dispositivo cinematográfico cuyo objetivo deliberado es, justamente, el establecimiento de una cierta distancia crítica con respecto a los testimonios entregados.

Lo que me interesa dejar claro aquí, finalmente, es que el mero hecho de poner en escena, de dar un rostro y una voz identificables a estas figuras del engaño, de la traición y de la tortura, y de situarlas junto a voces resistentes, es un gesto que pone en entredicho, por medio del texto fílmico, las retóricas oficiales de la transición, cuyas consignas oficiales fueron "la transparencia" y la neutralización de "los choques de fuerzas sociales y políticas ligadas al pasado traumático” (Richard, 2010, p. 31).

\section{Referencias}

Amorós, M. (2006). Chile: la Memoria como fuerza de la Historia. Récupéré sur Archivo Chile: http://www.archivochile.com/ Ideas_Autores/amorosm/1/1amorosm0016.pdf

Bedregal, X. (1999). La dictadura, gran máquina del olvido, convirtió a Chile en un país de amnesia general. Entrevista con Carmen Castillo. Consulté le enero 6, 2018, sur La Jornada: https://www.jornada.com.mx/1999/04/05/carmen-castillo.htm

Bruzzi, S. (2006). New Documentary. New York: Routledge.

Castillo, C. (Réalisateur). (1994). La Flaca Alejandra [Film]. Francia, Chile.

Comolli, J.-L. (1995). Mon ennemi préféré ? Images documentaires, 23, 45-56.

Daney, S. (2004). Sobre las voces en off, in, out, through. Dans M. Chion, La voz en el cine (pp. 167-171). Madrid: Cátedra.

Eltit, D. (1996). Cuerpos nómadas. Hispamerica, 25(75), 3-16.

Gómez-Barris. (2015). The Female Perpetrator. Dans A. J. Lebow, A Companion to Contemporary Documentary Film (pp. 524535). Somerset: Wiley-Blackwell .

Lazzara, M. (2012). Militancy Then and Now: A Conversation with Carmen Castillo. Journal of Latin American Cultural Studies, 1-14. Matus, A. (s.d.). Las imperdonables. Récupéré sur Los casos de la Vicaría: http://www.casosvicaria.cl/temporada-uno/las-impredonables/

Merino, M. (1993). Mi verdad: más allá del horror, yo acuso... Santiago de Chile: A. T. G.

Nichols, B. (2017). Introduction to Documentary. Bloomington: Indiana University Press.

Raymond, H. (2011). Carmen Castillo : pour une histoire des vaincus. Dans M. L. Sylvie Rollet, Théorème 14 : Théâtres de la mémoire - Mouvement des images(pp. 145-152). Paris: Sorbonne Nouvelle.

Richard, N. (2010). Crítica de la memoria. Santiago de Chile: Ediciones Diego Portales.

Traverso, A. (2017). La Flaca Alejandra: Post-Dictatorship Documentary and (No) Reconciliation in Chile. Critical Arts, 96-106.

Traverso, E. (2016). Mélancolie de gauche : la force d'une tradition cachée. Paris: La Découverte.

Valenzuela, V. (2006). Yo te digo que el mundo es así: giro performativo en el documental chileno contemporáneo. Doc On-line(1), 6-22.

$1 \quad$ Traducción del autor: “un langage visuel capable de prendre en charge l'éclipse de l'espoir socialiste et l'héritage des révolutions échouées du siècle dernier” (103). 
2 Para Valeria Valenzuela, el documental "performativo" implica "el registro de una búsqueda, en la cual el autor tiene que realizar movimientos para que los hechos ocurran” (Valenzuela, 2006, p. 13). Su concepción de la noción se basa, naturalmente, en la ya clásica subdivisión propuesta por Bill Nichols, quien distingue seis modalidades en la realización documental. La modalidad performativa, de acuerdo a Nichols, sería aquella en que "se enfatizan los aspectos subjetivos o expresivos de la implicación del propio cineasta con su sujeto” (Nichols, 2017, p. 22). La definición acaso más exacta y concreta es, sin embargo, la que ofrece Stella Bruzzi en su libro New Documentary, a la que adhiero también. Según la autora, uno de los aspectos esenciales del documental performativo sería la presencia no-problemática, dentro de la imagen, del autor, del cineasta. Traduzco aquí sus propias palabras: "Recientemente, emergen muchos documentales que dan por sentada la existencia y la inevitable presencia de sus realizadores, demostrando directamente la performatividad inherente al filme de no-ficción. La intervención abierta del cineasta señala de manera definitiva la muerte de la teoría documental de la idealización del film imparcial al preguntar, categóricamente y desde dentro del documental mismo: ¿Qué es un documental, sino un diálogo entre un cineasta, un equipo y una situación que, aunque existente antes de su llegada, ha sido irrevocablemente cambiada luego de esta?” (Bruzzi, 2006, p. 198).

Solo puede especularse con respecto a las motivaciones detrás de esta ceremonia pública de disculpas. Para Eltit, sin embargo, se trataría claramente de un intento por utilizar "la memoria como un mecanismo retórico para establecer discursos ideológicos que le posibiliten [a Merino] el acceso a un lugar social preponderante” (Eltit, 1996, p. 114). Nelly Richard, en armonía con esta interpretación, considera que "[l]a Flaca Alejandra paga la traición de la primera delación de militantes convertidos en víctimas con esta denuncia compensatoria de la entrega de los nombres de los victimarios, queriendo saldar su deuda moral con la sociedad con un suplemento restitutivo de contra-información” (Richard, 2010, p. 100).

$4 \quad$ Traducción del autor: "Castillo doesn't even formulate the issue of the fall of the house as a question when she talks with Merino on screen. On the contrary, and in the face of the abrasive personal and public history that connects the two women, against all logic Castillo neither directly confronts nor interrogates Merino. Rather, she quietly listens to the other's slow monologues, only interjecting now and then with brief observations or precise questions, yet always intensely observing Merino's every move and gesture”.

$5 \quad$ Traducción del autor: "it is plausible to assume that Merino, if not the direct source, was highly instrumental in the repressive agency's ability to locate the house” (99).

6 En la jerga de los agentes de los servicios secretos, el "poroteo" era el reconocimiento de "puntos de encuentro de dirigentes miristas” (Matus \$15), en el que Merino participaba activamente. La periodista Alejandra Matus consigna algunos detalles de la operación, que consistía en deambulaciones motorizadas a través de Santiago: "En cuanto ella reconocía a algún conocido, comenzaba a temblar. Así los agentes confirmaban la información que necesitaban. De este modo cayeron secuestradas decenas de personas, muchas de las cuales se encuentran hoy desaparecidas” (Matus $\$ 15)$.

$7 \quad$ Es en efecto Alicia Barrios quien aparece en este plano de una decena de segundos frente al Mural del Detenido Desaparecido y del Ejecutado Político, y no Marcia Merino, como señala equivocadamente Antonio Traverso en la página 101 de su artículo. La secuencia, montada sin observar la lógica temporal de los encuentros de Castillo con sus interlocutoras (el personaje de Alicia solo será introducido hacia el último cuarto del filme), induce ciertamente al error. Un análisis un poco más detenido de la imagen revela, sin embargo, la verdadera identidad de la mujer en cuestión. De abrigo negro y mallas deportivas blancas, fiel a su pasión por el artificio y el disfraz, Barrios reaparecerá utilizando el mismo atuendo hacia el final de la cinta, mientras camina junto a Castillo detrás de una gran placa mortuoria que lleva los nombres "Collins y Figueroa".

8 En Crítica de la memoria, Nelly Richard habla, por su parte, de "roturas biográficas".

9 Traducción del autor: "images that are often too dark to make out".

10 Traducción del autor: “Amis ou ennemis, les personnages d’un film partagent [un] ambigu destin scénique [...]. Non seulement ils appartiennent au même film, mais souvent au même cadre [...]. Entre eux naît une sorte de communauté cinématographique”.

11 Traducción del autor: "Castillo chooses to sit or stand in close proximity to Merino, as if in the company of an old comrade, rather than favoring an off-screen position, opposite her subject, as interviewers-or interrogators-would”.

12 La voz in, según Serge Daney, es generalmente la voz invisible de la entrevista, del reportaje en directo: “Aunque se emita fuera de campo, [esta] voz irrumpirá en la imagen (in), chocará contra un rostro, contra un cuerpo, provocará la aparición furtiva o duradera de una reacción, de una respuesta, en ese rostro, en ese cuerpo” (Daney, 2004, p. 169). Esta voz, elabora Daney, hace “pasar por la emergencia de la verdad lo que no es más que la producción, ofrecida al voyerismo del espectador, de la confusión del cobaya cuando se enfrenta al dispositivo-cine” (Daney, 2004, p. 170).

13 Traducción del autor: “Ce qui est intéressant dans ce film, c’est qu’avec Guy [Girard] on s'était donnés un mode d'emploi. Il n'y avait pas d'échange avec la Flaca avant le tournage. Toute notre relation devait être devant une caméra”.

14 Traducción del autor: "on était enfermés dans le discours de la Flaca, [...] [ce qui était] donc néfaste pour ce que je voulais raconter".

15 A este respecto, la propia Castillo reconoce: "Yo logro llegar con una emoción neutra, tratando que no salgan confusiones de culpabilidades ni perdones, con el objetivo de que el espectador decidiera. [V]engo a tratar de que hable de su relación con el torturador. Yo ya había trabajado mucho la situación de la tortura y sabía que en ese momento podía estar junto a ella sin juzgarla. Nos juntamos para hacer un trabajo y luego ella siguió su vida y yo la mía” (Bedregal, 1999). 